\title{
REPRESENTACIONES OFÍDICAS EN EL ARTE RUPESTRE DE ALVA (BONGARÁ, AMAZONAS-PERÚ): EL CULTO AL AGUA Y LAS REDES DE INTERACCIÓN INTERREGIONAL DURANTE EL FORMATIVO
}

\author{
Ophidic representations in the rock art of Alva (Bongará, \\ Amazonas-Perú): the cult of water and interregional \\ interaction networks during the Formative
}

\section{Anthony Alex Villar Quintana}

Maestrante en la especialidad de Arqueología Andina. Universidad Nacional Mayor de San Marcos. Perú.

ORCID: https://orcid.org/0000-0003-2452-7002, Correo-e: anthony.villar@unmsm.edu.pe

\section{Recibido: 16/2/2021 • Aprobado: 11/6/2021}

Cómo citar: Villar Quintana, A. A. (2021). Representaciones ofídicas en el arte rupestre de Alva (Bongará, Amazonas-Perú): el culto al agua y las redes de interacción interregional durante el Formativo. Ciencia y Sociedad, 46(3), 77-96. Doi: https://doi.org/10.22206/ cys.2021.v46i3.pp77-96

\section{Resumen}

El estudio de las pinturas rupestres plasmadas en un abrigo rocoso de la zona de Alva (distrito de Shipasbamba, provincia de Bongará, Amazonas-Perú) tuvo como objetivo determinar la función de ese abrigo durante el periodo Formativo, así como sus implicaciones en la formación del corpus iconográfico y su inserción en las redes de interacción interregional durante el referido periodo. El análisis iconográfico (compositivo y comparativo) de esas representaciones y la relación con su entorno nos permite plantear que durante el Formativo este abrigo rocoso funcionó como un santuario dedicado a las serpientes, relacionado a su vez con actividades de culto al agua, en una ruta que conectaba la Amazonia con los Andes.

Palabras clave: pinturas rupestres, serpientes, culto al agua, rutas interregionales, periodo Formativo.

\begin{abstract}
Investigation of the cave paintings covering a rock shelter in the Alva area (Shipasbamba district, Bongará province, Amazonas region, Peru) aimed to determine the function of said rock shelter during the Formative period, as well as its implications in the formation of the iconographic corpus and its insertion in the interregional interaction networks during said period. The iconographic analysis (compositional and comparative) of these representations and the relationship with their environment allows us to propose that during the Formative period this rocky shelter functioned as a sanctuary dedicated to snakes, and in turn related to water worship activities, in a route that connected the Amazon with the Andes.
\end{abstract}

Keywords: Rock paintings, snakes, cult of the water, interregional routes, Formative period. 


\section{Introducción}

La presencia de distintas especies de serpientes en todo el mundo y sus distintas características (reptante, hostil, venenosa, diseños en el cuerpo, etc.) han generado que la mayoría de las sociedades, por no decir todas, las hayan integrado dentro de su cosmovisión. En gran parte de América las serpientes se encuentran relacionadas al agua y a la fertilidad de la tierra (Carrión, 2005 [1955], p. 85; Gámez, 2018, pp. 121-133), lo cual provocó que estos animales fueran considerados como deidades a quienes se tenían que rendir distintos cultos.

Asimismo, muchas veces las serpientes fueron representadas con atributos de ave, como en el caso de Mesoamérica, sobre todo durante el periodo Clásico, donde es interpretada como una alegoría de que su control del agua también alcanza a la forma de esta como lluvia (Castellón, 2002, pp. 29-30). En el caso del Formativo peruano, se encuentran distintas representaciones de serpientes, muchas veces con atributos de otros seres (Tello, 1929, p. 72; 1961, pp. 237-238), las cuales también fueron plasmadas en arte rupestre.

Los estudios sobre el arte rupestre en Amazonas han ido en aumento durante los últimos años, siendo escasos hace algunas décadas, como lo demuestran Rogger Ravines (1986, p. 9) y Rainer Hostnig (2003, pp. 3-7) en sus respectivos inventarios de lugares con arte rupestre en el Perú. Actualmente, gracias a los aportes de Ruth Shady \& Arturo Ruiz (1987), Newman Aguilar (1997; 2002), César Olano (2005), Ulises Gamonal (2006), Arturo Ruiz (2007, 2009a, 2009b, 2015), Peter Arana \& Horacio Zuta
(2009), Klaus Koschmieder (2012, 2013), Quirino Olivera (2012), entre otros, mediante reportes e investigaciones, conocemos más acerca del arte rupestre amazonense.

Pretendemos entonces contribuir con el presente trabajo a los estudios sobre el arte rupestre Formativo ${ }^{1}$ nororiental. Por tanto, decidimos estudiar los motivos plasmados en uno de los abrigos rocosos de Alva, en la cuenca media-baja del río Utcubamba, en el distrito de Shipasbamba (provincia de Bongará, Amazonas), con el fin de conocer su función e importancia, tanto para las sociedades que habitaron el área como para quienes se movilizaron por ella durante el Periodo Formativo².

\section{Investigaciones en Bongará}

Las investigaciones arqueológicas en la provincia de Bongará son aún escasas; estas contribuciones se relacionan al registro de asentamientos en el alto Imaza (Montoya, 2006), cuevas funerarias en el distrito de San Carlos (Ruiz, 2010, pp. 195-199) y litoesculturas del periodo Formativo en Yambrasbamba (Villar, 2021). En cuanto al estudio de arte rupestre contamos con las referencias de Peter Arana \& Horacio Zuta (2009, pp. 43-55), Wilson Yomona (2017, pp. 127-142), Miuler Villar (2019) y Anthony Villar (2019, 2020, pp. 281-282), siendo estos últimos quienes informan sobre la presencia de arte rupestre Formativo en la provincia de Bongará.

\section{Investigaciones sobre el arte rupestre Formativo del nororiente peruano}

Los estudios sobre el periodo Formativo en el nororiente peruano han sido abordados por diversos

1. Parte de la información plasmada en este artículo formó parte de una ponencia titulada "El arte rupestre Formativo de Alva: representaciones ofídicas y su relación con el culto al agua en las rutas interregionales del norte peruano", presentada por el autor en el marco del I Congreso Internacional de Arte Rupestre Amazónico, llevada a cabo en la Universidad Nacional Toribio Rodríguez de Mendoza de Amazonas entre el 24 y el 27 de septiembre de 2019. El presente artículo cuenta con nuevos datos que fortalecen lo propuesto anteriormente.

2. La propuesta cronológica del Periodo Formativo utilizada en el presente trabajo corresponde a la planteada por la Misión Arqueológica de la Universidad de Tokio (Kato \& Seki eds. 1998 en Shibata, 2004, p. 82).

78 | Ciencia y Sociedad 2021; 46(3, julio-septiembre): 77-96•Artículos originales 
investigadores como Pedro Rojas (1985), Ruth Shady (1971, 1973), Ruth Shady \& Hermilio Rosas (1979), Jaime Miasta (1979), Ulises Gamonal (2006, 2011a), Atsushi Yamamoto (2008, 2012), Ryan Clasby \& Jorge Meneses (2012), Ryan Clasby (2014), Quirino Olivera $(2013,2014)$, Anthony Villar (2021) y Francisco Valdez (2013), este último en Zamora-Chinchipe (Ecuador). En conjunto, estas investigaciones han contribuido al entendimiento de las dinámicas sociales existentes para el periodo Formativo del nororiente peruano, así como sus relaciones con otras áreas de la Costa, los Andes y la Amazonía.

Los estudios del arte rupestre Formativo en el nororiente peruano son pocos; contamos así con los aportes de Ulises Gamonal (2006, pp. 15-17), quien realiza un registro fotográfico y descriptivo de los petroglifos del Pindo (San Ignacio-Cajamarca), Rumipampa I y Guayacán I (Jaén-Cajamarca); sin embargo, aún se sabe muy poco sobre estas manifestaciones culturales y sus posibles implicancias sociales durante el Formativo.

Los estudios de Jaime Miasta (1979, p. 189) y Arturo Ruiz (2017, p. 8) respecto a las pinturas rupestres de Faical (San Ignacio-Cajamarca) y sus observaciones de ciertos motivos correspondientes al periodo Formativo generan interrogantes referentes al estudio del arte rupestre en la cuenca del Chinchipe y su relación con distintos complejos arquitectónicos de este periodo en esa área.
Por otra parte, los trabajos de Miuler Villar (2019) sobre las pinturas rupestres de Tambo Viejo (Bongarál Luya-Amazonas) y Anthony Villar (2019) en Alva (Bongará-Amazonas) reportan motivos correspondientes al Formativo, de los cuales algunos corresponden a su fase inicial; esto lo consideramos un primer paso en el estudio acerca del desarrollo de las primeras "sociedades complejas" en esta área altoamazónica y sus relaciones con otras sociedades asentadas en distintas zonas ecológicas durante ese periodo.

\section{Ubicación y medio ambiente}

Políticamente, el abrigo rocoso de Alva se ubica en territorio de la comunidad del mismo nombre, anexo del distrito de Shipasbamba, provincia de Bongará, Amazonas (Perú) (Figura 1). Este abrigo se encuentra a una altitud aproximada de 1100 m.s.n.m., próxima a la confluencia de las aguas que descienden por la quebrada Alva con las del río Utcubamba, en la margen derecha de ambas fuentes hídricas.

En esta parte, el río Utcubamba forma un pongo o cañón (Figura 2), conocido como La Rabija, debido, según algunos lugareños, a la forma serpenteante que presenta y que además se asemejaría al movimiento ondulante de la cola de un animal. Es en este punto donde las aguas que descienden por la quebrada Alva caen estrepitosamente formando una cascada e interceptan al río Utcubamba. 


\section{Figura 1}

Planos de ubicación de Alva, en el distrito de Shipasbamba, provincia de Bongará-Amazonas

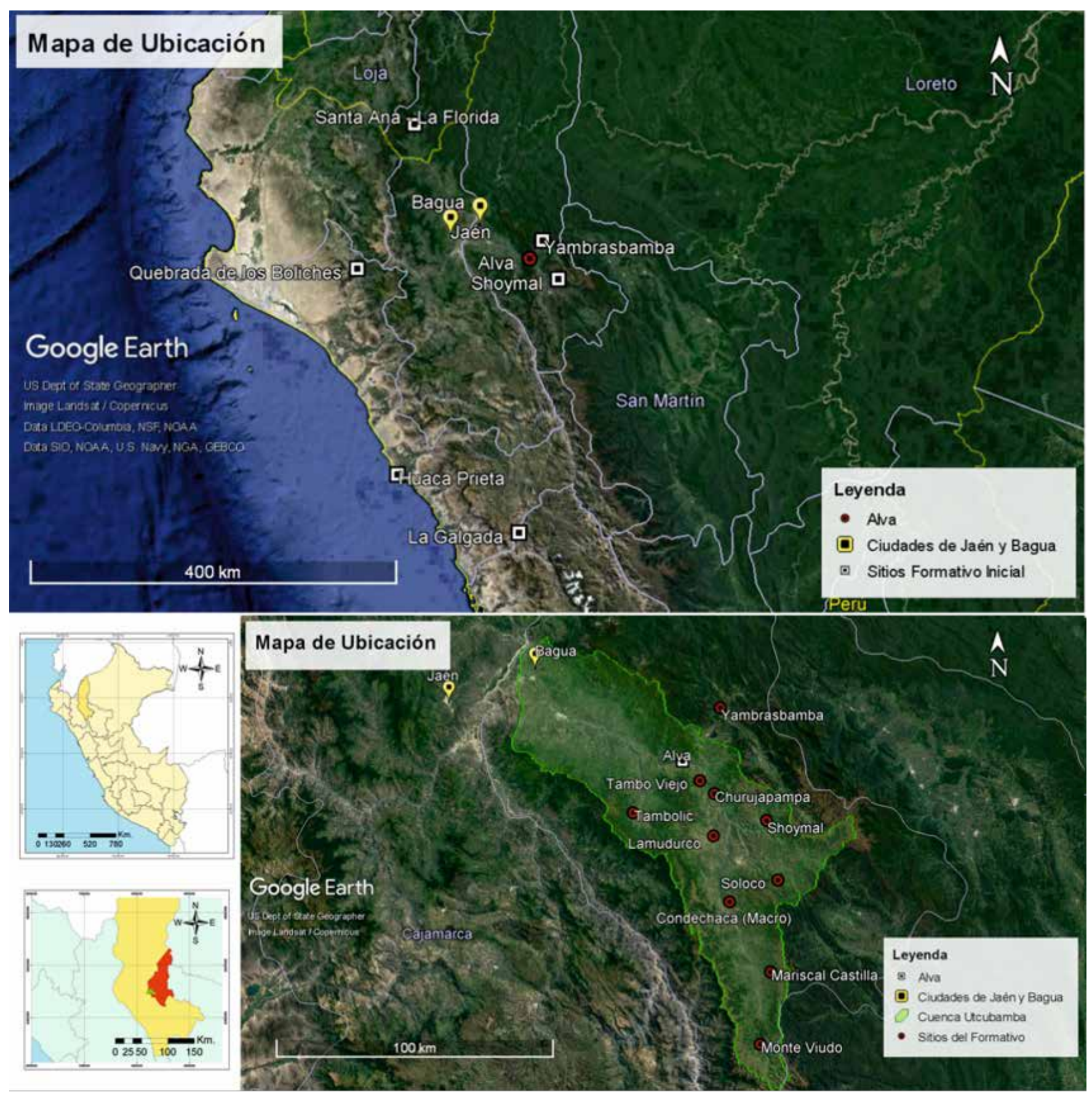

Notas. Superior: en referencia a otros sitios del Formativo Inicial en Perú y Ecuador, mencionados en el presente artículo. Inferior: Con relación a otros sitios Formativo de la cuenca media y alta del Utcubamba. Elaborado por el autor.

Como gran parte de la región Amazonas, el sitio se ubica en la denominada Amazonia Andina (Morales, 1998, p. 621), Andes Amazónicos (Kauffmann \&
Ligabue, 2003, p. 25) o Ceja de Selva (Pulgar, 1985, pp. 68-72), caracterizada por exhibir una multiplicidad de climas y paisajes de Bosque Pluvial Montano 
Bajo Tropical, con áreas cubiertas por copiosos bosques, que permite la presencia de diversas especies de flora y fauna. Según estudios paleoambientales y paleoclimáticos, el panorama del área habría sido el mismo hace 3500 años (Church \& Guegerich, 2017, p. 14).

Debido a la cercanía de la zona con la llanura amazónica de Bagua y su ubicación en un cañón, la zona de
Alva destaca por la presencia de una gran variedad de especies ofídicas, como la boa macanche (Boa constrictor ortonii), coral (género Micrurus), loro machaco (Bothrops bilineatus), jergón (Bothrops atrox) (Figura 2), etc., siendo esta última la causante del $90 \%$ de los accidentes por serpientes en la amazonia peruana (Ortiz et al., 2012, p. 198) y muchas muertes en el departamento de Amazonas (Rivera, 2015).

\section{Figura 2}

Fotografias referentes al entorno ambiental y el abrigo rocoso de Alva, en el distrito de Shipasbamba, provincia de Bongará-Amazonas
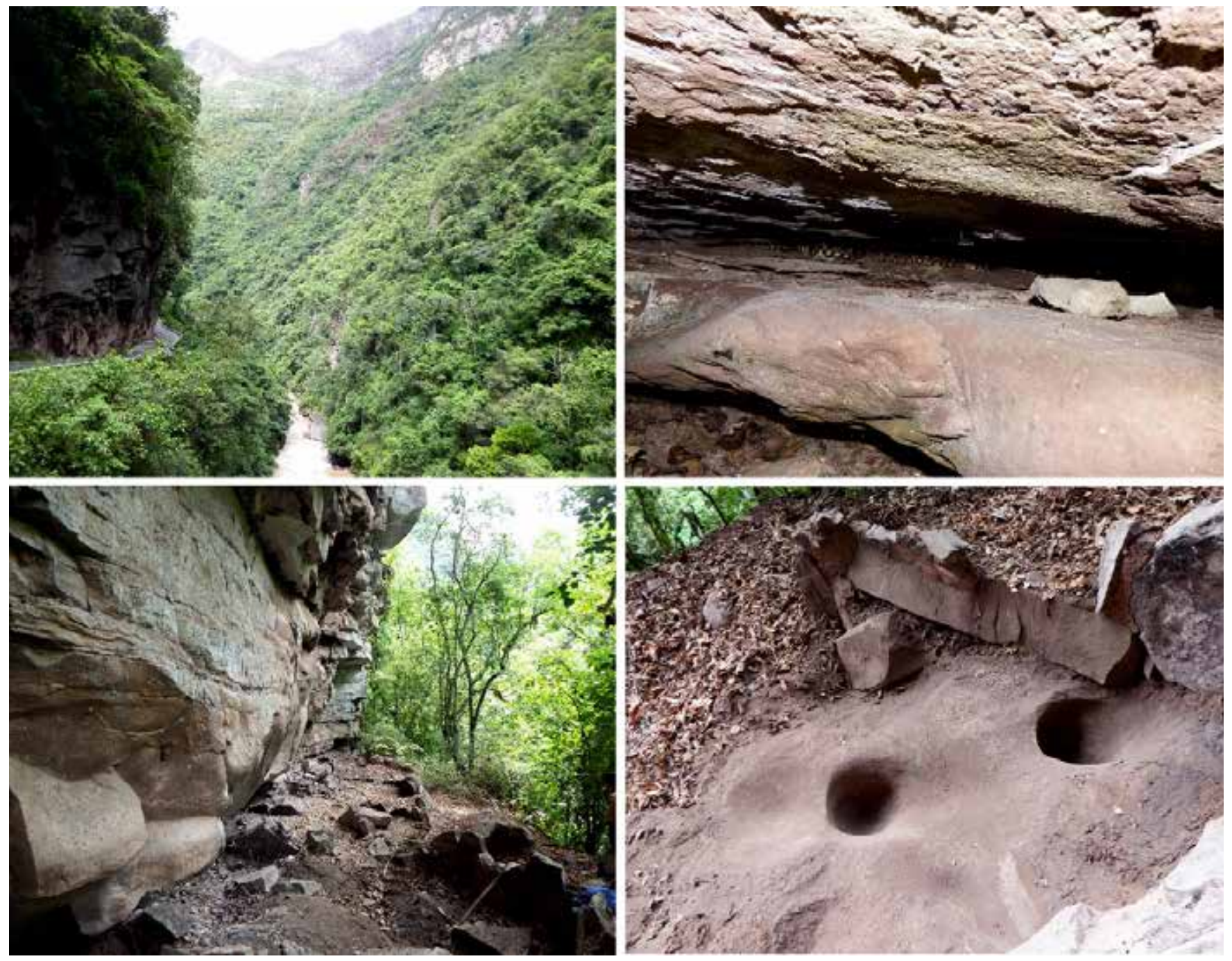

Notas. Superior izquierda: Cañón de Alva. Superior derecha: Serpiente jergón en la zona de Alva. Inferior izquierda: Abrigo rocoso donde se encuentran las pinturas rupestres de Alva y estructuras en su base. Inferior derecha: Piedra paccha en abrigo rocoso de Alva. Lámina elaborada por el autor. 


\section{Metodología}

La primera vez que visitamos el abrigo rocoso de Alva fue en el año 2013, regresando al lugar en enero de 2017 con el objetivo de fotografiar y describir las distintas manifestaciones culturales observadas en el lugar, principalmente el arte rupestre. Posteriormente en gabinete procesamos las fotografías referentes a los motivos en las pinturas rupestres, mediante el software DStretch ImageJ, lo cual facilitó una observación más clara de estas y una mayor fidelidad de la representación gráfica.

Una vez realizado el registro de los motivos plasmados en las pinturas rupestres de Alva, se procedió a identificar la posible filiación cultural y/o periodo al que pertenecían las distintas representaciones rupestres, tratando de ubicar representaciones del Periodo Formativo, ya que algunas de estas fueron observadas previamente en campo. Asimismo, se revisaron distintas fuentes bibliográficas y se tomó en cuenta las características ecológicas y biológicas del entorno inmediato (basándonos en propuestas de la arqueología de paisaje), que nos permitieron obtener algunos resultados que plasmamos en el presente trabajo.

\section{Entorno arqueológico}

La zona de Alva sirve de soporte para diversas expresiones culturales prehispánicas, como edificios de planta circular en las partes menos accidentadas, sarcófagos antropomorfos o purunmachu(s) asociados a pinturas rupestres y otros tipos de estructuras funerarias en partes inaccesibles de los acantilados. Este tipo de manifestaciones corresponde a periodos prehispánicos tardíos, principalmente vinculados a las distintas sociedades del territorio amazonense y áreas aledañas anexados posteriormente al Tahuantinsuyo.

\section{El abrigo rocoso de Alva}

Este abrigo (Figura 2), orientado hacia el oeste, constituye el soporte de las pinturas rupestres aquí tratadas. Cuenta con aproximadamente 16 metros de longitud, 7 metros de alto y 6 metros de profundidad. En su base pueden observarse estructuras con plantas de distintas formas (Figura 2 ), elaboradas con piedras planas colocadas de manera vertical, unidas con argamasa; una de estas estructuras presenta en su base una roca de gran tamaño con múltiples horadaciones (Figura 2), los cuales corresponden a la categoría de pacchas (véase Carrión, 2005 [1955], p. 35).

La base del abrigo presenta ciertos espacios excavados ilícitamente, donde se observan materiales culturales prehispánicos, quizá mezclados incluso con material moderno; observamos así mazorcas de maíz, pepas de lúcuma, pedúnculos de lagenarias, valvas de frejol y fragmentos de cerámica; destaca entre estos últimos un borde arqueado con aplicación serpentiforme, el cual según la secuencia realizada por Arturo Ruiz (2009 [1972], pp. 76-78) para el sitio de Kuélap correspondería a periodos tardíos en sus fases Kuélap y Kuélap-Inca.

La superficie rocosa del abrigo es irregular, presentando ciertas áreas lisas y otras onduladas, sobre las cuales se plasmaron pinturas rupestres en distintos colores como rojo, blanco, crema y naranja, representando aproximadamente 79 motivos distribuidos en nueve paneles, de los cuales 50 corresponden a motivos "figurativos" y 29 a los "no figurativos"3 (Tabla 1).

3. Consideramos como motivos "figurativos" a las representaciones zoomorfas, antropomorfas, fitomorfas, e hibridaciones de estas fáciles de reconocer; mientras que los "no figurativos" corresponden a motivos abstractos y geométricos.

82 | Ciencia y Sociedad 2021; 46(3, julio-septiembre): 77-96• Artículos originales 


\section{Tabla 1}

Distribución de motivos figurativos y no figurativos entre los 9 paneles con pintura rupestre, en el abrigo rocoso de Alva

\begin{tabular}{|c|c|c|c|c|}
\hline \multirow{2}{*}{\multicolumn{2}{|c|}{ Figurativo }} & \multicolumn{2}{|c|}{ Motivos } & \multirow{2}{*}{ Total } \\
\hline & & No figurativo & & \\
\hline \multirow{11}{*}{ 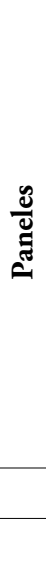 } & Panel 1 & 0 & 2 & 2 \\
\hline & Panel 2 & 8 & 13 & 21 \\
\hline & Panel 3 & 14 & 3 & 17 \\
\hline & Panel 4 & 9 & 9 & 18 \\
\hline & Panel 5 & 9 & 2 & 11 \\
\hline & Panel 6 & 2 & 0 & 2 \\
\hline & Panel 7 & 1 & 0 & 1 \\
\hline & Panel 8 & 6 & 0 & 6 \\
\hline & Panel 9 & 1 & 0 & 1 \\
\hline & Total & 50 & 29 & 79 \\
\hline & $\%$ & $63.29 \%$ & $36.71 \%$ & $100 \%$ \\
\hline
\end{tabular}

Algunos de los motivos figurativos nos permitieron distinguir su relación con ciertos estilos y, a su vez, con diferentes periodos. Por ejemplo, una figura antropomorfa en posición sedente con los brazos extendidos y un tocado en la cabeza ubicado en el panel 9 y los camélidos esquemáticos de los paneles 5 y 6 corresponderían a periodos tardíos (Intermedio
Tardío y/o Horizonte Tardío), ya que los mismos motivos se encuentran plasmados en distintos alfares locales (véase Ruiz, 2009 [1972], p. 164; 2009a, 2009b; Koschmieder, 2012, pp. 116-119).

Asimismo, entre los motivos más resaltantes en el abrigo rocoso de Alva se encuentra la representación de seis manos en positivo, sumándose a las halladas en ciertos sitios del nororiente peruano, como Poro Poro, en Santa Cruz-Cajamarca (Mac Kay et al., 1999 y Figura 5), Minshulay en la provincia de Chota-Cajamarca (Olivera, 2012, p. 400 y Figura 7) y Piedra Shapingo en la provincia de Utcubamba-Amazonas (Delgado, 2006, p. 24).

Las representaciones ofídicas fueron las que más llamaron nuestra atención debido a su cantidad y alto grado estético (con relación a las demás representaciones), constituyendo el $48 \%$ de los motivos figurativos y el $77.4 \%$ de los motivos zoomorfos (Tabla 2). Estas representaciones también corresponden a distintos estilos y momentos de elaboración, lo cual será expuesto en un futuro trabajo, pues para la presente investigación solo tomaremos en cuenta los motivos ofídicos considerados como pertenecientes al periodo Formativo, en base a su correlación estilística.

\section{Tabla 2}

Distribución de los motivos antropomorfos y zoomorfos en las pinturas rupestres de Alva

\begin{tabular}{|c|c|c|c|c|c|c|c|c|}
\hline & \multirow{2}{*}{\multicolumn{7}{|c|}{ Motivos figurativos }} & \multirow{4}{*}{ Total } \\
\hline & & & & & & & & \\
\hline & \multicolumn{3}{|c|}{ Antropomorfos } & \multicolumn{3}{|c|}{ Zoomorfos } & & \\
\hline & Cuerpos & Manos & Rostros & Ofidios & Camélidos & Cánidos (?) & & \\
\hline \multirow{9}{*}{$\frac{\mathscr{\Xi}}{\Xi}$} & Panel 1 & 0 & 0 & 0 & 0 & 0 & 0 & 0 \\
\hline & Panel 2 & 2 & 0 & 0 & 6 & 0 & 0 & 8 \\
\hline & Panel 3 & 1 & 0 & 1 & 12 & 0 & 0 & 14 \\
\hline & Panel 4 & 4 & 0 & 0 & 4 & 0 & 1 & 9 \\
\hline & Panel 5 & 4 & 0 & 0 & 1 & 4 & 0 & 9 \\
\hline & Panel 6 & 0 & 0 & 0 & 0 & 1 & 1 & 2 \\
\hline & Panel 7 & 0 & 0 & 0 & 1 & 0 & 0 & 1 \\
\hline & Panel 8 & 0 & 6 & 0 & 0 & 0 & 0 & 6 \\
\hline & Panel 9 & 1 & 0 & 0 & 0 & 0 & 0 & 1 \\
\hline \multicolumn{2}{|l|}{ Total } & 12 & 6 & 1 & 24 & 5 & 2 & 50 \\
\hline \multicolumn{2}{|l|}{$\%$} & $24 \%$ & $12 \%$ & $2 \%$ & $48 \%$ & $10 \%$ & $4 \%$ & $100 \%$ \\
\hline \multirow{2}{*}{$\begin{array}{c}\% \text { por categoría } \\
\text { (Antropomorfo/Zoomorfo) }\end{array}$} & & $63.2 \%$ & $31.6 \%$ & $5.2 \%$ & $77.4 \%$ & $16.1 \%$ & $6.5 \%$ & \\
\hline & & $100 \%$ & & & $100 \%$ & & & \\
\hline
\end{tabular}

Nota. Destacan por su cantidad los motivos ofídicos, seguidos por los antropomorfos. 
Representaciones ofídicas en el arte rupestre Formativo de Alva

Entre las representaciones ofídicas distinguimos cinco motivos atribuibles al periodo Formativo, tomando en cuenta ciertas características diagnósticas (correlación estilística); por otro lado, usando criterios de superposición y asociación con relación a estas, consideramos la misma acepción cronológica para otras cinco, siendo posible que muchas de las 14 restantes sean contemporáneas a estas. En el presente trabajo solo describiremos los motivos con atributos estilísticos diagnósticos de ese periodo.

La representación ofídica con más características diagnósticas del periodo Formativo se ubica en la parte central del panel 2, plasmada en rojo, crema y blanco; corresponde a una serpiente bicéfala con cabezas de ave (Figuras 3.1, 3.2 y 3.3), al parecer de rapińa, de cuya parte inferior emerge una serpiente enrollada con ojos circulares y boca recta, asimismo se puede distinguir la representación de lo que corresponderían a plumas en su lado derecho (según el observador).

\section{Figura 3}

Representaciones de serpientes bicéfalas con cabezas de ave, plasmadas sobre distintos soportes en diversos sitios del Formativo Inicial
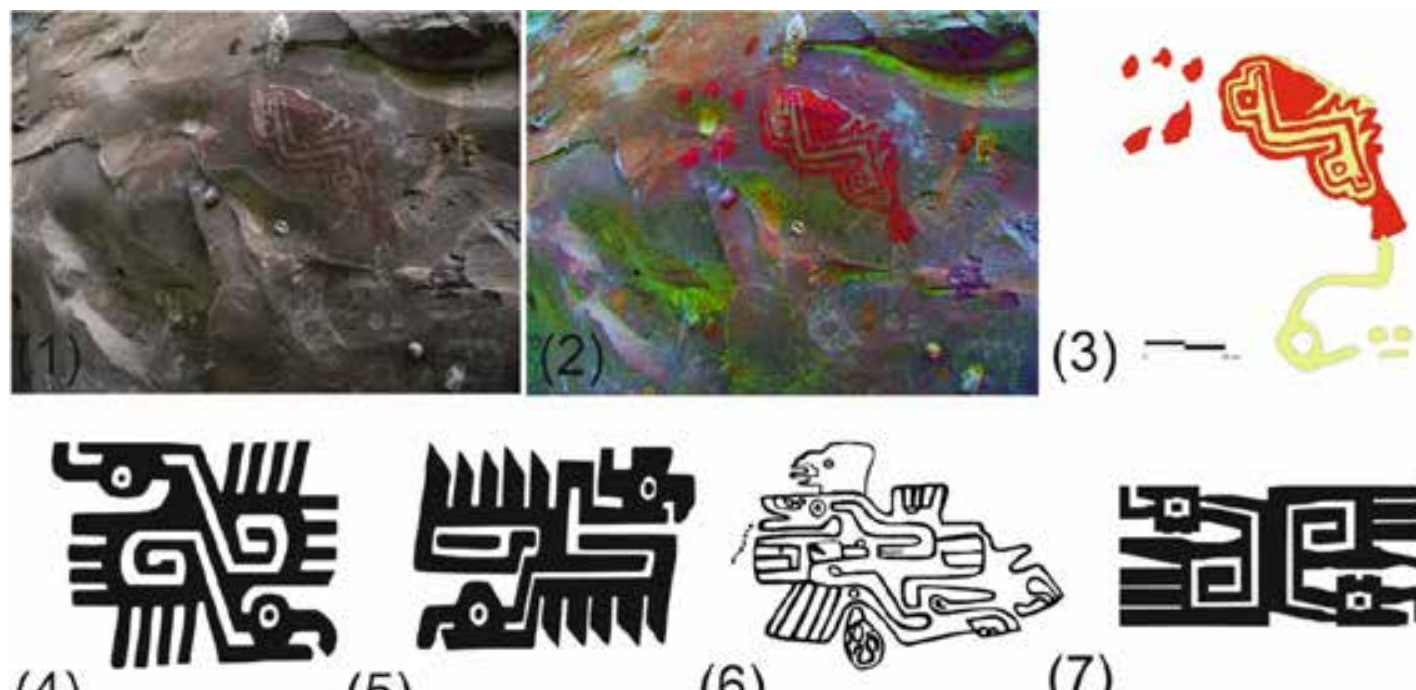

(4)

(5)
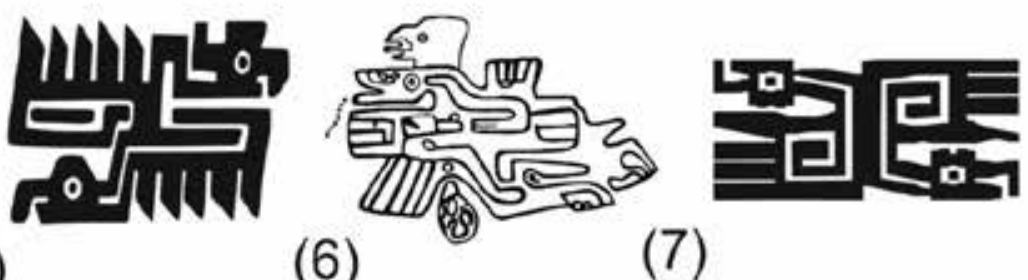

(7)

(8)
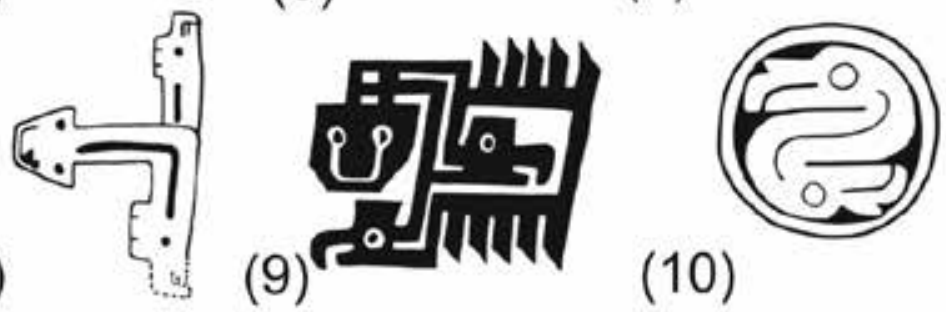

(11)

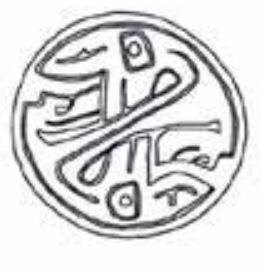

Notas. Fotografía (1), imagen mejorada en DStretch Image J canal "ybr"(2) y dibujo de un motivo plasmado en el panel 2 del abrigo rocoso de Alva (3), correspondiente a una serpiente bicéfala con cabezas de aves. Dibujos relacionados al mismo motivo, en distintos soportes del Formativo Inicial como: los textiles de La Galgada (4, 5 y 9) y Huaca Prieta (7), cuenco lítico de Santa Ana-La Florida (8) y la zona de Bagua/Jaén (11), petroglifo de Quebrada de los Boliches (6) y mate grabado de Huaca Prieta (10). Lámina elaborada por el autor con base en Grieder (1988) (4, 5 y 9), Bird et al. (1985) (7 y 10), Núñez (1986) (6), Valdez (2013) (8) y Clasby (2014) (11). 
Este representación corresponde al mismo motivo plasmado en los textiles de sitios como La Galgada (Figuras 3.4, 3.5 y 3.9), en Pallasca-Ancash (Grieder, 1988, Figuras 130 y 139) y Huaca Prieta (Figura 3.7), en Ascope-La Libertad (Bird, 1964, Figura 2; Bird et al., 1985, Figuras 120, 122 y 139), donde también se encuentra esa representación en la tapa de un mate tallado (Bird, 1964, Figura1; Bird et al., 1985, Figura 43) (Figura 3.10).

Este mismo motivo también fue plasmado en uno de los petroglifos de Quebrada de los Boliches (Figura 3.6), en Olmos-Lambayeque (Falcón, 2006, Figura 10; Guffroy, 2009, Figura 36; Núnez, 1986, Figuras 16 y 17) y en un cuenco de piedra pulida con grabados en Santa Ana La Florida (Figura 3.8), en Palanda (Zamora Chinchipe-Ecuador) que, a su vez, es similar a otro cuenco ubicado en el "Museo Hermógenes Mejía Solf” (Figura 3.11), Jaén-Cajamarca (Clasby, 2014, Figura 9.25; Olivera 2008, Figura 6; Valdez, 2013, Figuras 11 y 12). Para los sitios mencionados se considera una antigüedad promedio de 4000 años (véase Bischof, 2015, p. 141), por lo cual se enmarcaría en el Formativo Inicial (Figura 1).

Otra de las representaciones ofídicas del periodo Formativo también se encuentra en el panel 2, ubicado en la parte inferior derecha del motivo descrito anteriormente. Fue plasmado en color blanco y crema, y corresponde a una serpiente bicéfala con los ojos redondeados y boca recta (Figura 4.1); de una de sus cabezas se desprende a manera de apéndice otra serpiente con un rostro similar, asociado a lo que parece ser una boca con colmillos en color rojo, la cual pudo elaborarse posteriormente.

Esta representación por su composición (serpiente bicéfala) y cualidad artística (rostro con ojos redondeados y boca recta) sería contemporánea con el motivo descrito anteriormente. Asimismo, en la parte inferior izquierda del panel 2 observamos la representación de otra serpiente bicéfala (Figura 4.2), cuyas facciones del rostro solo son visibles en una de sus cabezas, con los ojos redondeados y boca triangular de aspecto sonriente.

La representación de serpientes bicéfalas es muy recurrente, aunque no exclusiva, en el Formativo Inicial, siendo plasmadas en textiles de sitios como La Galgada (Grieder, 1988, Figuras 144 y 146), Huaca Prieta (Bird et al., 1985, Figura 131) y Asia, en Cañete-Lima (Engel, 1963, Figura 192), de los cuales podemos considerar los rasgos faciales como características diagnósticas; corresponden a dos ojos redondos y una boca sonriente.

Los motivos ofídicos bicéfalos de Alva (Figuras 4.1 y 4.2) podrían corresponder al Formativo Inicial, junto a otros ejemplares en la cuenca del Utcubamba (Amazonas), en las pinturas rupestres referentes de Cerro Mito, provincia de Luya (Figura 6.4) y Tambo Viejo en la provincia de Bongará/Luya (Figura 6.2) (Figura 1), donde se representaron a serpientes bicéfalas sonrientes de cuya cabeza derecha (según el observador) emerge otra serpiente, siendo la misma composición observada en uno de los motivos de Alva (Figura 4.1).

Por su parte, de los doce motivos ofídicos identificados en el panel 3 destacan dos representaciones debido a sus composiciones artísticas. La primera está plasmada en la izquierda del panel y fue elaborada con tonalidades de blanco y crema, corresponde a una serpiente de cuerpo robusto (Figura 4.3), quizá la representación de una boa constrictor o macanche, enrollada en dos partes de su largo cuerpo; esta representación además destaca por poseer los ojos redondeados y una boca sonriente. 


\section{Figura 4}

Representaciones de serpientes con distintas composiciones artísticas en el abrigo rocos de Alva
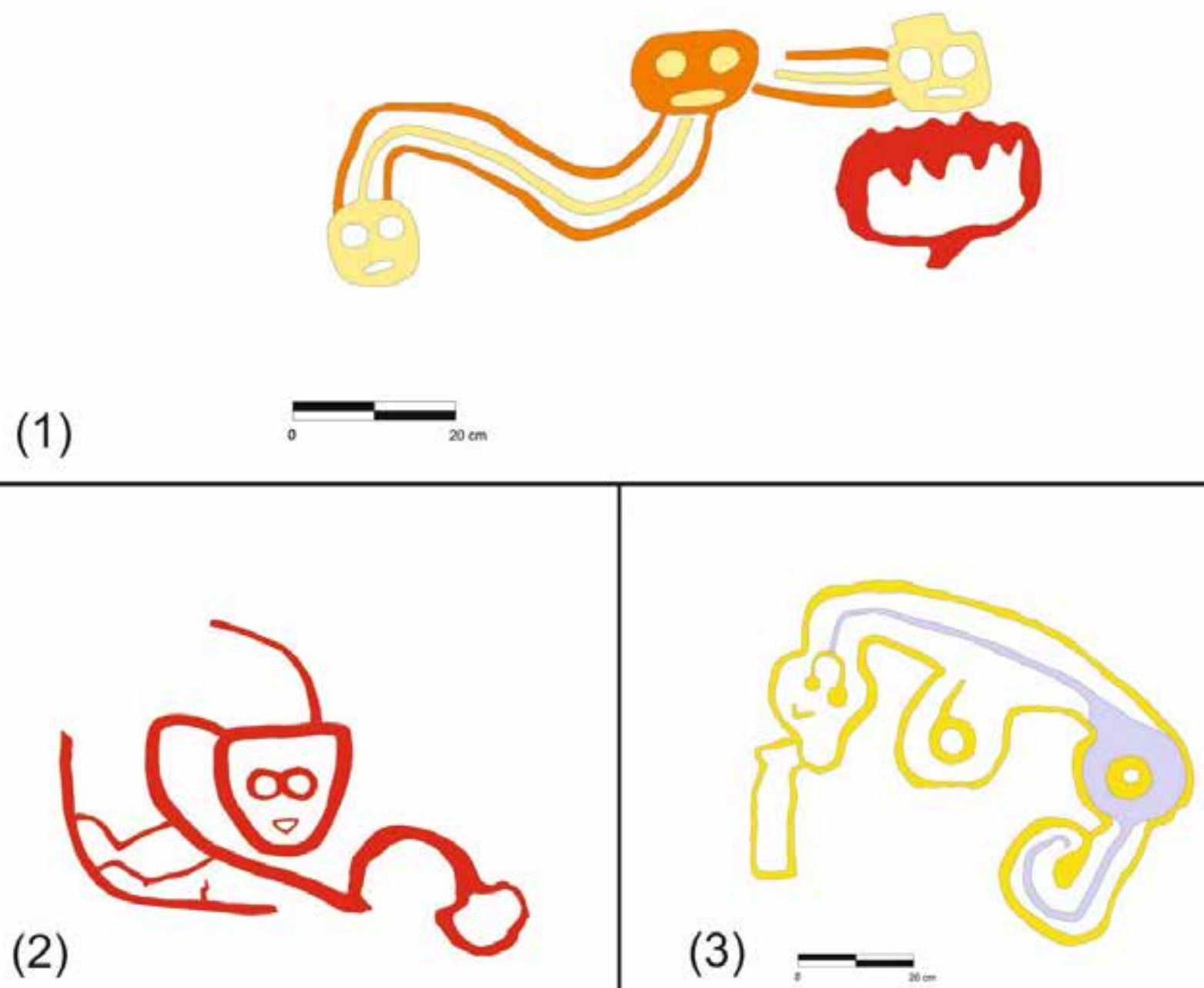

Notas. Dibujos de motivos plasmados en el panel 2 del abrigo rocoso de Alva, correspondiente a serpientes bicefalas (1 y 2). Dibujo de un motivo plasmado en el panel 3 del abrigo rocoso de Alva, correspondiente a una serpiente enrollada con rostro sonriente (3). Dibujos elaborados por el autor.

El segundo motivo abarca casi toda la parte inferior del panel y corresponde a una representación en zigzag de color blanco con líneas perpendiculares, que sería la representación geometrizada de una serpiente (Figura 5), ya que parte de esta presenta líneas entrecruzadas y zigzagueantes que recuerdan al cuerpo de un ofidio, muy similar al motivo plasmado en un mural de Casual, en Bagua (Olivera,
2014, Figura 149), que corresponde a un sitio muy próximo a Alva; ese mural estaría asociado a fechados que indican una antigüedad promedio de $2000+/-30$ años (Olivera, 2014, p. 196), siendo así posterior al Formativo Tardío, correspondiente al periodo denominado como Epiformativo por parte de Peter Kaulicke (2010, p. 404). 
Representaciones ofídicas en el arte rupestre de Alva (Bongará, Amazonas-Perú): el culto al agua y las redes de interacción interregional durante el Formativo

\section{Figura 5}

Fotografia e imagen mejorada en DStretch Image J canal "lab" de un motivvgo en zigzag del panel 3 en el abrigo rocoso de Alva
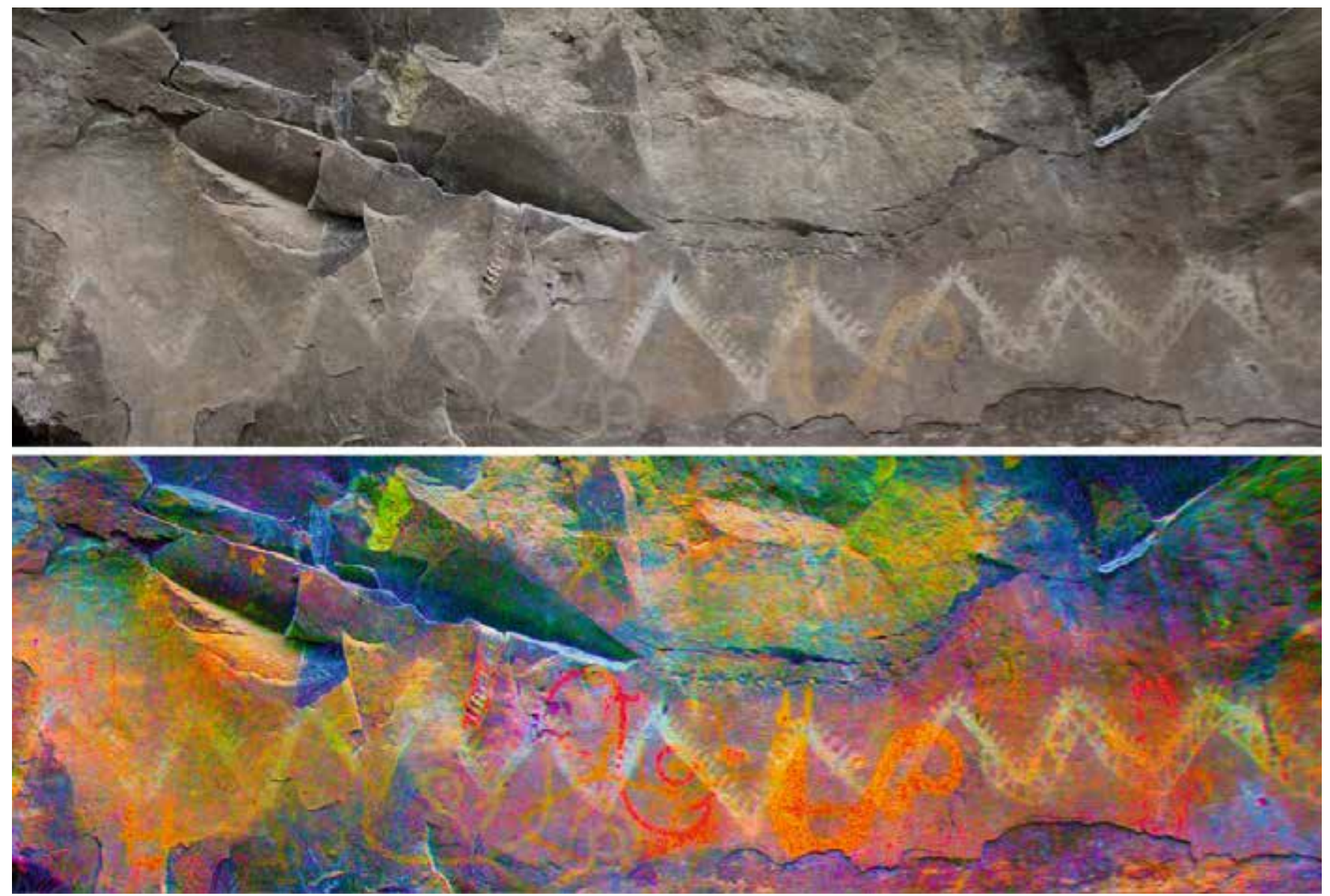

Notas. La imagen correspondería a una serpiente geometrizada. Fotografías del autor.

Representaciones ofídicas en el arte rupestre Formativo de la cuenca media del Utcubamba

Uno de los motivos más recurrentes del periodo Formativo corresponde a la "serpiente sonriente", cuya representacion habría sido plasmada desde el Formativo Inicial en los petroglifos de La Galgada (Bueno \& Grieder, 1988, Figura 153; Bueno, 1997, Lám. 2), los textiles de Huaca Prieta (Bird, 1964, Figura 6; Bird et al., 1985, Figuras 110 y 111), etc., y habría continuado en las fases posteriores del Formativo, como en la litoescultura de sitios como La Pampa, en el Valle de Santa, Ancash (Bischof,
2015, Figura 93) y Chawin Punta, en la cuenca del Chaupihuaranga, Pasco (Brown, 2017, Figura 8).

En la cuenca del Utcubamba, Amazonas, existen otros sitios con representaciones en pinturas rupestres de la llamada "serpiente sonriente", como en Tambolic, en la Provincia de Utcubamba (Figura 6.1) y Churujapampa, en la provincia de Bongará (Figura 6.3) (Figura 1), sumándose a estos algunas de las representaciones del abrigo de Alva (Figuras 4.2 y 4.3). Cabe resaltar que en Tambo Viejo (Provincia de Bongarál Luya), Miuler Villar (2019) registró distintos motivos del periodo Formativo, los cuales, en su mayoría, corresponden a serpientes (Figura 6.2). 


\section{Figura 6}

Representaciones de "serpientes sonrientes" en pinturas rupestres de la cuenca del Utcubamba

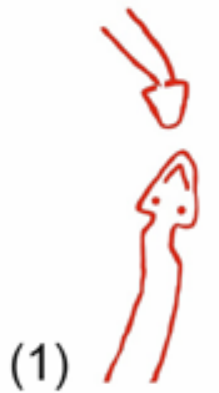

(3)

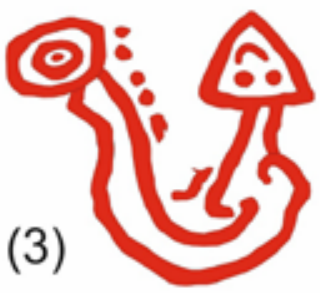

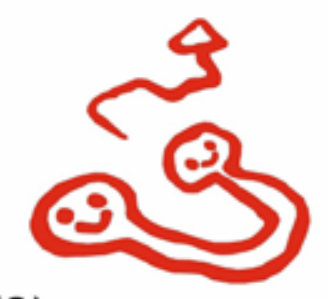

(2)

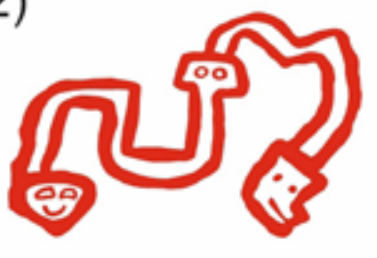

(4) rocoso de Alva pertenecientes al Formativo.

\section{Función del abrigo rocoso durante el Formativo}

Desde la arqueología de paisaje, se entiende que uno o más elementos de un entorno son en sí mismas entidades animadas y/o potencialmente activadas mediante ciertas acciones que expresan interacción, negociación o resignificación (Lozada \& Vigliani, 2019); en donde el arte rupestre, entendido como una obra artificial intencionalmente permanente y generalizada del hombre sobre su medio (Boado, 1993, p. 40), cuenta con un rol importante en esta conexión, relacionada con aspectos cosmológicos que influyen en los diferentes planos de cada sociedad, sobre todo en lo religioso, político y económico.

La ubicación del abrigo rocoso de Alva en un cañón que une la llanura amazónica con la zona andina de Amazonas, por donde además fluye el caudaloso río Utcubamba, alimentado por diversas fuentes hídricas como la cascada de Alva, nos incentiva a considerar que la elección del abrigo rocoso como soporte de las pinturas rupestres durante el Formativo se relacionaría a su cercanía con estas fuentes hídricas, sin descartar que en períodos posteriores tuvieron una connotación similar.

\section{Discusiones}

El Simposio Arqueología y Paisaje del Arte Rupestre Formativo en la Costa Norte del Perú, realizado en el año 2004, nos demostró el gran potencial que tiene el estudio del arte rupestre Formativo para el entendimiento de las sociedades desarrolladas durante ese periodo. Los trabajos de este importante evento desarrollaron temáticas relacionadas con la distribución espacial del arte rupestre Formativo, la relación con asentamientos del periodo y otros elementos del paisaje circundante, la definición de estilos regionales y la inserción de estos en las redes de comunicación (Kaulicke et al., 2015, pp.18-24). Siguiendo esta línea de estudios, a continuación se evalúan las implicancias de las representaciones plasmadas en el abrigo
Es innegable el rol que cumplió el culto al agua en el mundo andino y amazónico (Véase Carrión, 2005 [1955]; Millones, 2013). Este culto se encontraría ligado a muchos lugares con arte rupestre, incluso durante el Periodo Formativo, como en el caso de Poro Poro-Udima (Mac Kay et al., 1999, p. 396). La relación de los ofidios con ese culto es muy estrecha, ya que estos animales evocan tanto a fuentes hídricas como pluviales (Carrión, 2005 [1955], p. 85). Asimismo, este culto se relaciona a la fertilidad agrícola, idea que no estaría ausente durante el Formativo (Campana, 1995, p. 43; Kaulicke, 1976, p. 35), como en el caso de los petroglifos ubicados en Quebrada de los Boliches (Guffroy, 2009, p. 44), La Galgada y Quebrada Morín (Bueno, 2006, p. 82). 
La ubicación de Alva en un medio ambiente, que habría sido el mismo desde hace más de 3500 años (véase Church \& Guengerich, 2017, p. 14), donde la fauna predominante corresponde a ofidios, se relaciona con la temática de las pinturas rupestres plasmadas en ese abrigo desde el periodo Formativo. Esto demuestra la importancia que habría tenido el área durante el referido periodo en las dinámicas de veneración a los ofidios y, por ende, al agua, así como a la fertilidad de la tierra para actividades agrícolas.

Uno de los motivos más sobresalientes en el arte rupestre Formativo del abrigo rocoso de Alva corresponde a una serpiente bicéfala con cabeza de ave. Su representación, como lo mencionamos anteriormente, corresponde a un motivo muy recurrente durante el Formativo Inicial (Bischof, 1999, p. 104), periodo en el cual existió cierta diversidad de motivos plasmados en el arte rupestre (Véase Bischof, 2015; Falcón, 2006; Falcón \& Suárez 2009; Tsurumi \& Morales 2013).

Esta serpiente bicéfala con cabezas de ave muestra a un ser mítico (Valdez, 2013, p. 122; Bischof, 2015, p. 141) y su representación en distintos soportes atañe a un posible indicador de complejización social, ya que su aceptación y difusión demuestra la existencia de una fuerte cohesión ideológica (Valdez, 2013, p. 121), teniendo a este factor como el impulsor de la construcción de grandes templos, aparejada a la realización de rituales y ofrendas, vinculados al surgimiento de grandes complejos como el de Caral (Shady, 1999, pp. 13-15).

Es probable que la fusión de ave-serpiente en el imaginario religioso Formativo Inicial, y posterior a este, se encuentre relacionado con el culto al agua de fuentes pluviales (lluvia, granizo, etc.), representados por el ave y las fuentes hídricas o fluviales (ríos, riachuelos, etc.) relacionadas con la serpiente.

Por su parte, la existencia del motivo ofídico geometrizado en el arte rupestre de Alva, que es similar al hallado en un mural de Casual (Bagua), por lo cual consideramos que pertenece al periodo Epiformativo (fines del Formativo), nos indicaría que las actividades ligadas con el culto al agua, en un área que consideramos un santuario de ofidios, se habría mantenido aún durante finales del Formativo e incluso habría continuado durante los periodos siguientes.

Es importante mencionar la leyenda recogida en Bagua por Ruth Shady (1973, p. 140), donde una serpiente apoya a los nativos en contra de las tropas inca en el Marañón; así como las historias recopiladas por Ulises Gamonal (2011a, p.17) sobre la existencia de fuerzas sobrenaturales ligadas a serpientes en el centro ceremonial Formativo de Montegrande, Jaén-Cajamarca. Se demuestra con lo anterior la existencia de un rezago actual y modificado referente a la importancia de los ofidios en periodos prehispánicos y su relación con ríos y centros ceremoniales en el nororiente peruano.

\section{Implicaciones en las rutas interregionales}

La distribución del arte rupestre en muchos casos respondería a una organización del paisaje mediante la geografía de distintos lugares y los desplazamientos humanos por estos (Boado, 1993, p. 40). Próximas al abrigo rocoso de Alva, se encuentran las áreas de Jaén y Bagua, que son de igual manera puntos importantes de interacción durante el Formativo entre la zona andina y amazónica, del norte peruano y el sur ecuatoriano (Shady, 1987, pp. 459-461; Yamamoto, 2012, pp. 9-29), y durante periodos posteriores. Esta interacción habría sido permitida mediante rutas terrestres que siguieron las cuencas hidrográficas tributarias del Marañón y favorecida aún más por la baja altitud de la cadena montañosa andina en el norte de Perú.

El río Utcubamba constituye uno de los afluentes más importantes del Marañón, los cuales se unen en Bagua, zona donde existe una amplia ocupación para el Formativo; además, se encuentra próxima a Alva. Esto nos indica que Alva se encontraría 
dentro de una ruta importante durante el Formativo, comprendiéndose como un punto de peregrinaje, donde se rendía culto a las serpientes y al agua. El yacimiento salífero (en líquido) que se encuentra cerca de Alva, en la zona denominada Salinas, en territorio de Shipasbamba (Bongará-Amazonas), fortalece nuestra idea de un gran flujo de personas que se movilizaron por esta área.

Esta idea se refuerza aún más por la existencia de otros sitios con evidencias del Periodo Formativo en la cuenca del Utcubamba, algunos ya mencionados en párrafos anteriores, como Tambolic (en la Provincia de Utcubamba), Churujapampa, Tambo Viejo (en la provincia de Bongará) y Cerro Mito (en la provincia de Luya). En Lamudurco, provincia de Luya (Koschmieder, 2012, p. 36), las inmediaciones de Mariscal Castilla (Cabrera, 2018, comunicación personal), Purum Llacta de Soloco (Crandall, 2017, p. 289), Condechaca (Macro) (Rojas, 1961, p. 20, ver Láminas sobre cerámica) y Monte Viudo ${ }^{4}$ (Guengerich, 2017, pp. 95-98), en la provincia de Chachapoyas, fueron registrados alfares del Periodo Formativo. En Shoymal (provincia de Chachapoyas) se registró arquitectura y litoesculturas que, al parecer, corresponderían al Formativo Inicial (Villar 2021).

Cabe resaltar que en la colección del señor Wilson Yomona se observó un objeto lítico de filiación Formativa, similar a algunos ejemplares de la cuenca del Chinchipe; este artefacto, según su posesionario, procede del sitio de Goshcata en la provincia de Bongará, lugar ubicado en la cuenca media del Utcubamba. Estas interacciones no solo se habrían centrado en la cuenca del Utcubamba, ya que existen otros sitios como Yambrasbamba (Villar, 2021), en la cuenca del Imaza, que presentan litoesculturas con representaciones similares a las de Alva y otros sitios ubicados a gran distancia en la Costa, los Andes y la Amazonía (Figuras 1 y 3).

Se entiende así que la ocupación y uso de toda la cuenca del Utcubamba durante el Formativo devela la existencia de rutas interregionales, no solo entre la llanura amazónica (provincia de Bagua) y la zona amazónica-andina (provincias de Bongará, Luya y Chachapoyas) del actual Amazonas, sino también en un área mucho más grande que incluyó también sitios de la Costa. En estas rutas se encontró la zona de Alva, como un santuario que habría surgido en el Formativo Inicial y continuado posteriormente y, además, como parte del sistema de circulación de distintos productos y conocimientos.

\section{Vinculaciones con el desarrollo artístico del periodo Formativo}

Actualmente sabemos que muchos de los sitios monumentales y más notorios del periodo Formativo, como Chavín, recibieron influencias de distintos focos (Burger \& Salazar, 2008, pp. 100-103); habría ocurrido lo mismo con los elementos artísticos, muchos de los cuales correspondieron a expresiones que fueron complejizándose y formando el corpus artístico característico del Formativo, en postrimera a su fase inicial, al obviarse, modificarse o agregarse nuevos elementos iconográficos (Bischof, 2015, pp. 138-160; Campana, 1995, p. 25).

Ciertas representaciones del periodo Formativo Inicial en el abrigo de Alva formarían, junto a otras, los antecedentes del posterior corpus artístico del norte peruano. Consideramos así que la representación concerniente a la serpiente bicéfala con cabezas de ave rapaz (Figura 2), habría sido modificada para formar las representaciones cefálicas de aves rapaces en la cerámica de Pacopampa (Figura 7.1), cuya

\footnotetext{
4. La fase inicial de Monte Viudo corresponde a un momento de transición, del final del Formativo a inicios de un periodo posterior (Guengerich, 2017, p. 95), con fechados que oscilan entre los 400 a.C. y 50 d.C., lo cual se podría asociar, en parte, al Epiformativo, periodo denominado de esta manera por Peter Kaulicke (2010, p. 404) para referirse a un momento de transición a fines del periodo Formativo, aproximadamente a partir del 200 a.C.
}

90 | Ciencia y Sociedad 2021; 46(3, julio-septiembre): 77-96• Artículos originales 
manufactura, según Daniel Morales (2005 [1980], p. 251, Figuras 17 y 52), correspondería al Formativo Medio; esta misma representación se observa también en la cerámica Formativa de Bagua (Figura 7.3) (véase Olivera, 2015, p. 80; Shady \& Rosas, 1979, Figura 145).

Algo similar ocurre con las representaciones de la llamada "serpiente sonriente" que, como mencionamos anteriormente, constituyó un motivo muy común durante el Formativo Inicial que abarcó una amplia área, desde el norte hasta el centro-sur peruano. Estos motivos fueron plasmados con ciertas variantes en la cerámica de Pacopampa (Figura 7.2) (véase Morales, 2005 [1980], Figuras 13, 14 y 63), La Pampa (véase Bischof, 2015, p. 148, Figura 93) y Chawin Punta (véase Brown, 2017, p. 97, Figura 8).

El motivo correspondiente a la serpiente bicéfala con un tercer ofidio emanando de una de las cabezas, plasmado tanto en el abrigo rocoso de Alva como en otros lugares de Amazonas, como en Cerro Mito y Tambo Viejo, se habría manifestado con ciertos atributos agregados en sitios posteriores del Formativo en el norte peruano; un ejemplo de estos corresponde a una de las pinturas rupestres de Santa Ana (Figura 7.4) en la provincia de Contumazá, Cajamarca (véase Castillo, 2008, Lám. 2).

A pesar del limitado número de ejemplos presentados, podemos argüir que existió una continuidad de las principales representaciones del norte peruano y el sur ecuatoriano, en algunos casos resaltando solo una parte de estos motivos, como las cabezas de la llamada "serpiente sonriente" y del ave rapaz que anteriormente formaba parte de una representación ofídica bicéfala; mientras que en otros casos fueron complejizándose por medio de la adición de ciertos rasgos característicos de estilos formativos desarrollados posteriormente, como en el caso presentado para la representación de Santa Ana, en Cajamarca.

\section{Figura 7}

Representaciones del periodo Formativo correspondiente a aves y serpientes estilizadas
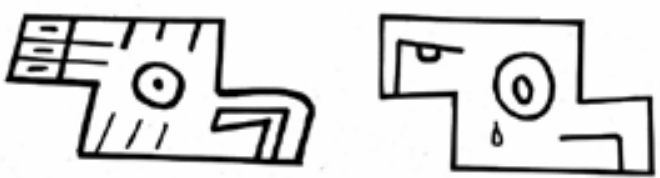

(1)

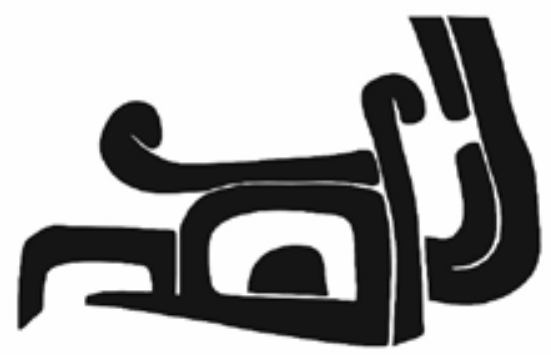

(3)

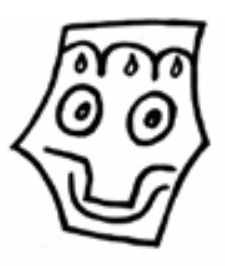

(2)

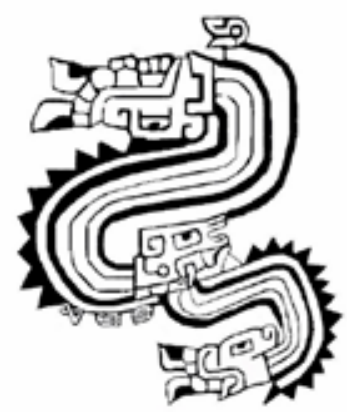

(4)

Notas. Motivos correspondientes a cabezas de aves rapaces en la cerámica de Pacopampa (1) y Bagua (3). Rostro de serpiente sonriente en Pacopampa (2). Motivo representado en las pinturas rupestres de Santa Ana, en la provincia de Contumazá, Cajamarca (4). Lámina elaborada por el autor con base en Morales 2005 [1980] (1 y 2), Olivera 2015 (3) y Castillo 2008 (4). 


\section{Conclusiones}

Los datos presentados en este artículo, basados principalmente en el estudio del arte rupestre Formativo plasmado en el abrigo rocoso de Alva, la relación de este con su entorno inmediato, así como sus conexiones y similitudes con otras representaciones en distintos sitios y soportes, nos permiten argumentar lo siguiente:

El abrigo rocoso de Alva habría constituido el soporte de representaciones plasmadas en pinturas rupestres desde el periodo Formativo Inicial.

Durante el Formativo, y probablemente en periodos posteriores, el abrigo rocoso de Alva constituyó un santuario ligado al culto al agua, relacionado con su ubicación dentro de un cañón y en la unión de dos fuentes fluviales con aguas torrentosas, cuya área posee abundancia de especies ofídicas (ligadas al agua en la cosmovisión andina y amazónica) relacionadas directamente con las representaciones de ese abrigo rocoso; donde resalta una representación común del Formativo Inicial correspondiente a un híbrido serpiente-ave, al parecer relacionado al ciclo hídrico fluvial y pluvial.

La cuenca del río Utcubamba constituyó un área de tránsito interregional durante el Formativo, lo que implicó la circulación de individuos, productos y conocimientos, entre la zona amazónica y andina. Justamente esta ruta permitió el intercambio comercial entre distintas zonas ecológicas y, por lo tanto, el desarrollo de una cosmovisión en cada área, que para cierto momento del periodo Formativo Inicial habría presentado concepciones comunes en distintos lugares, expresados en un motivo iconográfico (Figura 3).

Las representaciones plasmadas en Alva, junto a otras del norte peruano y sur ecuatoriano, forman parte de una tradición muy difundida, tanto en áreas de floresta tropical como en las andinas y costeńas; la misma que habría contribuido a la formación de corpus artísticos más complejos en fases posteriores a las del periodo Formativo, cuando precisamente destacaron centros ceremoniales como los de Chavín, Pacopampa y Kuntur Wasi.

\section{Agradecimientos}

A Miuler Villar, Elizabeth Quintana, Eugenio Gallac, Salatiel Rojas, Felipe Marín, Wilson Yomona, Francisco Medina, Cecilia Jaime Tello, Luisa Díaz, Bradymir Bravo, Arturo Ruiz Estrada, Pedro Novoa, Rainer Hostnig, Franklin Montalvo, Diego Cabrera, José Luis Palomino y Nicholas Brown, quienes de diversas maneras hicieron posible la realización del presente trabajo.

\section{Referencias}

Aguilar, N. (1997). El Área histórico-Cultural de Chillao y Luya. Lamud.

Aguilar, N. (2002). Pictografías de La Laguna de los Cóndores. En Whitehead et al., (eds.). International Rock Art Congress proceedings. Vol. 2. Tucson.

Arana, P. \& Zuta, H. (2009). Arte rupestre en la región Amazonas. Para conocer, valorar y conservar. Jazán.

Bird, J. (1964). El Arte Precerámico de Huaca Prieta. Revista Peruana de Cultura, (3), 121-129.

Bird, J., Hyslop, J. \& Skinner, M. (1985). The Preceramic Excavations at the Huaca Prieta, Chicama Valley, Perú. The American Museum of Natural History New York.

Bischof, H. (1999). Los mates tallados de Huaca Prieta:¿Evidencias del arte Valdivia en el Arcaico centroandino? Boletín de Arqueología PUCP (3), 85-119.

Bischof, H. (2015). El arte de Chavín: Precursores y desarrollo temprano. En Fux, P. (ed.). Chavin (pp. 138-160). Museo de Arte de Lima.

Boado, C. (1993). Límites y posibilidades de la Arqueología de Paisaje. SPAL: Revista de Prehistoria y Arqueología, (2), 9-55. 
Brown, N. (2017). Chawin and Chavín: evidence of interregional interaction involving the peruvian central highlands during the late Initial Period. Nawpa Pacha: Journal of Andean Archaeology, 37(2). 87-109. https://doi.org/ $10.1080 / 00776297.2017 .1390354$

Bueno, A. \& Grieder, T. (1988). Petroglyphs. En Grieder, T., Bueno, A., Earle, C. y Malina, R. (eds.). La Galgada, Perú. A Preceramic Culture in Transition (pp. 182-184). University of Texas Press.

Bueno, A. (1997). Los cóndores y La Galgada. Petroglifos como textos gráficos. Espacio, (36), 54-61.

Bueno, A. (2006). Petroglifos en la quebrada Morín y La Galgada: de los textos gráficos al mito etiológico. Investigaciones Sociales, (17), 67-90. https://doi.org/10.15381/is.v10i17.7048.

Burger, R. \& Salazar, L. (2008). The Manchay Culture and the Coastal Inspiration. En Conklin, W. \& Quilter, J. (eds.). Chavin: Art, Architectures, and Culture (pp. 85-105). Cotsen Institute of Archaeology Press. University of California.

Campana, C. (1995). Una deidad antropomorfa en el Formativo Andino. A \& B Editores.

Carrión, R. (2005 [1955]). El Culto al Agua en el Antiguo Perú. Instituto Nacional de Cultura.

Castellón, B. (2002). Cúmulo de símbolos. La serpiente emplumada. Arqueología Mexicana, (53), 28-35.

Castillo, D. (2008). Las pinturas rupestres del Río Seco de Santa Ana, Jurisdicción de San Benito, Cajamarca. Revista del Museo de Arqueología, Antropologia e Historia, (10), 239-248.

Church, W. \& Guengerich, A. (2017). Introducción: La reconstrucción de Chachapoyas a través de la historia e historiografía. Boletín de Arqueología PUCP, (23), 5-38. https:// doi.org/10.18800/boletindearqueologiapucp. 201702.000

Clasby, R. \& Meneses, J. (2012). Nuevas investigaciones en Huayurco: Resultados iniciales de las excavaciones de un sitio de la ceja de selva de los Andes peruanos. Arqueología y Sociedad, (25), 303-326.

Clasby, R. (2014). Exploring Long Term Cultural Developments and Interregional Interaction in the Eastern Slopes of the Andes: A Case study from the site of Huayurco, Jaén Region, Perú. [Tesis de doctorado, Yale University].

Crandall, J. (2017). El desarrollo espacial de las comunidades Chachapoyas bajo la dominación colonial inka y española. Boletín de Arqueologia PUCP, (23), 283-311. https:// doi.org/10.18800/boletindearqueologiapucp. 201702.010

Delgado, Y. (2006). La Piedra Shapingo: un mito o una realidad. En Gamonal, U. (ed.). El Arte Rupestre en el Nor Oriente Peruano. Facetas 55. Año 30 (p. 24). Jaén.

Engel, F. (1963). A Preceramic Settlement on the Central Coast of Peru: Asia, Unit 1. Transactions of the American Philosophical Society, 53(3), 1-139.

Falcón, V. (2006). La litoescultura de Jaiva y las representaciones rupestres preformativas. Arkeos. Revista Electrónica de Arqueología PUCP, 1(5), 1-16.

Falcón, V. \& Suárez, M. (2009). El felino en la emergencia de la civilización en los Andes Centrales. En: Sepúlveda, M.; Briones, L. y Chacama, J. (Eds.). Crónicas sobre la piedra: Arte rupestre de las Américas. VII Simposio Internacional de Arte Rupestre. Capitulo 4 (pp. 331-348). Universidad de Tarapacá.

Gámz, A. (2018). La serpiente de agua en la cosmovisión y ritualidad de los Ngiguas de San Marcos Tlacoyalco, Puebla, México. Antropología Experimental, (18), 121-134.

Gamonal, U. (2006). El Arte Rupestre en el Nor Oriente Peruano. Facetas, (55), 1-22.

Gamonal, U. (2011a). La huaca de las serpientes (Montegrande-Jaén). Facetas, (61), 17.

Gamonal, U. (2011b). Cultura del Alto Marañón (Alto Amazónica). Facetas, (62), 11-14. 
Grieder, T. (1988). Fiber Arts. En Grieder, T.; Bueno, A., Earle, C. y Malina, R. (eds.). La Galgada, Perú. A Preceramic Culture in Transition (pp. 152-181). University of Texas Press.

Guengerich, A. (2014). Monte Viudo: residential architecture and the everyday production of space in a chachapoya community [Tesis de doctorado, University of Chicago].

Guffroy, J. (2009). Imágenes y Paisajes rupestres del Perú. Universidad San Martín de Porres y Institut de recherche pour le Dèveloppement.

Hostnig, R. (2003). Arte Rupestre del Perú. Inventario Nacional. Concytec.

Kauffmann, F. \& Ligabue, G. (2003). Los Chachapoya (s): moradores ancestrales de los Andes amazónicos peruanos. Universidad Alas Peruanas.

Kaulicke, P. (1976). El Formativo de Pacopampa. Seminario de Historia Rural Andina. Universidad Nacional Mayor de San Marcos.

Kaulicke, P. (2010). Las cronologías del formativo. 50 años de investigaciones japonesas en perspectiva. Pontificia Universidad Católica del Perú.

Kaulicke, P., Tsurumi, E. \& Morales, C. (2015). Arqueología y Paisaje del Arte Rupestre Formativo en la Costa Norte del Perú. Boletín SIARB, (29), 18-24.

Koschmieder, K. (2012). Jucusbamba: Investigaciones arqueológicas y motivos Chachapoya en el norte de la Provincia de Luya, Departamento Amazonas, Perú. Tarea Asociación Gráfica Educativa.

Koschmieder, K. (2013). Arte Rupestre en la Provincia de Luya, departamento Amazonas. Revista del Museo de Arqueología, Antropología e Historia, (12), 167-205.

Lozada, J. \& Vigliani, S. (24-27 de septiembre de 2019). La seducción de los riscos. Arte rupestre en la laguna Mensabak, Selva Lacandona. Ponencia presentada en el "I Congreso Internacional de Arte Rupestre Amazónico”, Chachapoyas: Universidad Nacional Toribio Rodríguez de Mendoza de Amazonas.

Mac Kay, M., Cruz, R. \& del Carpio, M. (1999). Arte rupestre en el sitio Formativo de Poro
Poro, Sierra Norte del Perú. BIRA, (26), 393-402.

Montoya, M. (2006). Investigaciones arqueológicas en la cuenca del río Imaza (Bongará- amazonas). Revista Identidad Cultural. INC-Amazonas, 23-24.

Morales, D. (1998). Historia Arqueológica del Perú (del paleo-lítico al imperio Inca). Compendio Histórico del Perú. Editorial Milla Batres.

Morales, D. (2005). El Dios Felino en Pacopampa. Arqueologia y Sociedad, (16), 215-290.

Miasta, J. (1979). El Alto Amazonas. Arqueología de Jaén y San Ignacio, Perú. Seminario de Historia Rural Andina. Universidad Nacional Mayor de San Marcos.

Millones, L. (2013). Divinidades bajo las aguas. Apus Graph Ediciones.

Núñez, A. (1986). Petroglifos del Perú. Panorama mundial del arte rupestre. Vol. 1. Proyecto Regional de Patrimonio Cultural y Desarrollo.

Olano, C. (2005). Pintura Rupestre en Lonya grande. II Simposio Nacional de Arte Rupestre. Trujillo.

Olivera, Q. (2012). Arte rupestre en la cuenca del Marañón, regiones de Amazonas y Cajamarca, Perú. Investigaciones Sociales, 16(28), 397-402. https://doi.org/10.15381/is.v16i28.7414

Olivera, Q. (2013). Avance de las investigaciones arqueológicas en la alta Amazonia, nororiente de Perú. En Valdez, F. (ed.). Arqueología Amazónica. Las civilizaciones ocultas del bosque tropical (pp. 181-209). IFEA, IRD y Ediciones Abya-Yala.

Olivera, Q. (2014). Arqueología Alto Amazónica. Los orígenes de la civilización en el Perú. Asociación Los Andes de Cajamarca y Yanacocha.

Ortiz, C., Lazo, F., Bellido, C., Gonzales, E., \& Yarlequé, A. (2012). Variaciones en las actividades enzimáticas del veneno de la serpiente Bothrops atrox" jergón”, de tres zonas geográficas del Perú. Revista peruana de medicina experimental y salud pública, 29, 198-205. 
Pulgar, J. (1985). Las tres selvas del Antisuyo. Boletin de Lima, (39), 59-72.

Ravines, R. (1986). Arte Rupestre del Perú. Inventario General (Primera aproximación). Instituto Nacional de Cultura.

Rivera, J. (17 de septiembre de 2015). Amazonas: mujer muere por mordedura de serpiente venenosa. RPP Noticias. https://rpp.pe/peru/ actualidad/amazonas-mujer-muere-por-mordedura-de-serpiente-venenosa-noticia-836641

Rojas, P. (1961). Exploración arqueológica al Alto Marañón. Tomo III. Museo Nacional de Antropología y Arqueología de Lima/Wenner-Gren Foundation of New York.

Rojas, P. (1985). La "Huaca" Huayurco, Jaén. En Silva, F., Espinoza, W. y Ravines, R.(eds.) Historia de Cajamarca. Tomo I. Arqueología (pp. 181-186). Instituto Nacional de Cultura.

Ruiz, A. (2007). Chanque: Un Santuario de Arte Rupestre en la Región de Amazonas. En Hostnig, R., Strecker, M. y Guffroy, J. (eds.). Actas del Primer Simposio Nacional de Arte Rupestre. Cusco. Instituto Francés de Estudios Andinos.

Ruiz, A. (2009 [1972]). La alfarería de Kuelap: tradición y cambio. Avqi Ediciones.

Ruiz, A. (2009). El arte rupestre de Pollurua en Paclas, Amazonas, Perú. http://www.rupestreweb. info/pollurua.html

Ruiz, A. (2009). Las pinturas rupestres de Choclic, Lamud (Amazonas-Perú). http://www.rupestreweb.info/choclic.html

Ruiz, A. (2010). Amazonas: arqueología e historia. Universidad Alas Peruanas.

Ruiz, A. (2015). Mashumachay: expresiones rupestres en la provincia de Chachapoyas. http://www. rupestreweb.info/mashumachay.html

Ruiz, A. (2017). El arte rupestre de Faical. El Torreón. Noviembre-diciembre, 8.

Shady, R. (1971). Bagua, una secuencia del Periodo Formativo en la cuenca inferior del Utcubamba [Tesis de bachillerato, Universidad Nacional Mayor de San Marcos].
Shady, R. (1973). La arqueología de la cuenca inferior del Utcubamba [Tesis de doctorado, Universidad Nacional Mayor de San Marcos].,

Shady, R. (1987). Tradición y cambio en las sociedades formativas de Bagua, Amazonas, Perú. Revista Andina, (2), 457-487.

Shady, R. (1999). La religión como una forma de cohesión social y manejo político en los albores de la civilización en el Perú. Boletin del Museo de Arqueología y Antropología de la UNMSM, (9), 13-15.

Shady, R. \& Rosas, H. (1979). El Complejo Bagua y el Sistema de Establecimiento Durante el Formativo en la Sierra Norte del Perú. Nawpa Pacha, (17), 109-154. https://doi. org/10.1179/naw.1979.17.1.006

Shady, R. \& Ruiz, A. (1987). Arte rupestre en Amazonas-Perú. Boletín de Lima, (53), 12-13.

Tello, J. (1929). Antiguo Perú. Primera Época. Comisión Organizadora del Segundo Congreso Sudamericano de Turismo.

Tello, J. (1961). Chavin. Cultura Matriz de la Civilización Andina. Universidad Nacional Mayor de San Marcos.

Tsurumi, E. \& Morales, C. (2013). Un gato con muchas vidas: Un petroglifo Arcaico Tardío en el valle medio de Jequetepeque (Perú). Mundo de Antes, (8), 141-157.

Valdez, F. (2013). Mayo Chinchipe. Hacia un replanteamiento del origen de las sociedades complejas en la Civilización Andina. En Valdez, F. (ed.). Arqueología Amazónica. Las civilizaciones ocultas del bosque tropical (pp. 107-153). Instituto Francés de Estudios Andino; Institut de recherche pour le Dèveloppement y Ediciones Abya-Yala.

Villar, A. (24-27 de septiembre de 2019). El arte rupestre formativo de Alva: representaciones ofidicas y el culto al agua en las rutas interregionales. Ponencia presentada en el I Congreso Internacional de Arte Rupestre Amazónico. Chachapoyas: Universidad Nacional Toribio Rodríguez de Mendoza de Amazonas. 
Villar, A. (2020). Purumllaqta de Cuimal y el área de San Jerónimo (Amazonas) durante la hegemonía inca. Investigaciones Sociales, 22(42), 275-285. https://doi.org/10.15381/ is.v22i42.17493.

Villar, A. (08 de enero de 2021). Shoymal: Un Sitio del Periodo Formativo en la Cuenca Media del Utcubamba, Amazonas. Ponencia presentada en la $61^{\circ}$ Reunión Anual del Institute of Andean Studies.

Villar, M. (24-27 de septiembre de 2019). Manifestaciones de Tambo Viejo. Ponencia presentada en el I Congreso Internacional de Arte Rupestre Amazónico. Chachapoyas: Universidad Nacional Toribio Rodríguez de Mendoza de Amazonas.
Yamamoto, A. (2008). Ingatambo: un sitio estratégico de contacto interregional en la zona norte del Perú. Boletín de Arqueología PUCP, (12), 25-51.

Yamamoto, A. (2012). Las rutas interregionales en el Periodo Formativo para el norte del Perú y el sur de Ecuador: Una perspectiva desde el sitio Ingatambo, valle de Huancabamba. Arqueologia y Sociedad, (25), 9-34.

Yomona, W. (2017). Semblanzas y tesoros de mi pueblo. Aldo Editores Importadores SAC. 